\title{
Perception of Menstrual Normality and Abnormality in Spanish Female Nursing Students
}

\author{
Ana Abreu-Sánchez ${ }^{1}\left(\mathbb{D}\right.$, María Laura Parra-Fernández ${ }^{2}$, , María Dolores Onieva-Zafra ${ }^{2}(\mathbb{C}$ \\ and Elia Fernández-Martínez ${ }^{1, *(\mathbb{D})}$ \\ 1 Department of Nursing, University of Huelva, 21071 Huelva, Spain; abreu@denf.uhu.es \\ 2 Department of Nursing, Physiotherapy and Occupational Therapy, University of Castilla-La-Mancha, \\ Ciudad Real, 13071 Ciudad Real, Spain; marialaura.parra@uclm.es (M.L.P.-F.); \\ mariadolores.onieva@uclm.es (M.D.O.-Z.) \\ * Correspondence: elia.fernandez@denf.uhu.es
}

Received: 10 August 2020; Accepted: 1 September 2020; Published: 3 September 2020

\begin{abstract}
Menstrual problems are usually taboo; and often, some, such as dysmenorrhea, are presumed normal. This study seeks to compare the menstrual characteristics and symptoms of female university students reporting self-perceived normality concerning their cycles and menstruation with those who perceive their menstruation as being abnormal. A cross-sectional descriptive study was conducted among 270 nursing students using a self-report questionnaire that included sociodemographic and gynecological issues, together with Visual Analog Scale, the Andersch and Milsom Scale, and the Spanish version of the EuroQol-5 Dimension (EuroQol-5D) to measure self-perceived health status. A bivariate analysis was performed using the chi-square test, linear trend chi-square, and Student's $\mathrm{t}$-test, and a multivariate analysis of stepwise binary logistic regression was performed to predict the perception of cycle abnormality. In total, $77.4 \%$ of participants displayed normality; however, in self-reporting of menstrual characteristics, $67.4 \%$ identified alterations. Young women suffering from menstrual dizziness were $1.997(\mathrm{CI} 95 \%=1.010-3.950 ; p=0.047)$ more likely to manifest abnormal menstruation, $4.518(\mathrm{CI} 95 \%=1.239-16.477 ; p=0.022)$ more likely if they suffered from Grade 3 menstrual pain, and $2.851($ C195\% $=1.399-5.809 ; p=0.004)$ more likely if they perceived that menstruation interfered with their daily lives. Many menstrual changes and symptoms are still considered normal, making it difficult to identify and address these issues. Therefore, it is necessary to develop health policies and strategies to improve menstrual health literacy for increased knowledge and earlier diagnosis.
\end{abstract}

Keywords: disorders menstrual; menstrual experiences; menstrual health

\section{Introduction}

Normal menstruation is considered to occur every 24 to 38 days, on a regular basis, with bleeding that lasts 4.5 to 8 days, and 5 to $80 \mathrm{~mL}$ blood loss per cycle [1,2]. During the first menstrual cycle after menarche, alterations affecting the menstrual cycle are common, and are considered characteristics of the immaturity of the hypothalamic-pituitary-gonadal system. This is usually manifested by irregular cycles and anovulatory cycles [3]. In recent years, numerous studies have focused on the study of menstrual problems in young people, because, although they are usually not serious, they can have an impact on their daily activities and repercussions at the academic level [3-7]. The main gynecological problem affecting women of childbearing age is dysmenorrhea, for which two types exist: primary dysmenorrhea (which is not associated with any diagnosed pelvic pathology), and secondary dysmenorrhea (which is related to an identified cause) [8]. Primary dysmenorrhea is the most common form, which usually manifests at menarche, or a few months later, and is mainly related to an excess 
of prostaglandins, and can be accompanied by various other symptoms, such as nausea, vomiting, diarrhea, tiredness, or insomnia [8]. A recent international meta-analysis estimated the prevalence of dysmenorrhea in university students at $74.9 \%$ (C195\% 62.9-84.0) [4]. In Spain, the prevalence of dysmenorrhea has been estimated at $73.8-74.8 \%$ among university students $[9,10]$; corresponding to about $63.3 \%$ affected by primary dysmenorrhea and $10.5 \%$ by secondary dysmenorrhea [10]. In addition, other menstrual disorders, such as hypermenorrhea, menstrual irregularity, and other menstrual symptoms are less explored, both internationally and in Spain [11,12]. The aims of the published studies are very heterogeneous, although most focus on the prevalence, risk, protective factors, and impacts on their lives [4,12-14].

Previous studies have identified that young women with menstrual problems often do not consult health professionals for a variety of reasons, including normalization of disturbances, feelings of shame, lack of trust in the health professional, and lack of knowledge of menstrual normality [14-16]. This phenomenon of avoidance of consultation for menstrual problems is observed in young people worldwide [17], and also, specifically, in Spain [9,18], identifying a high percentage of women who self-medicate to address their menstrual problems [18]. Along these lines, the literature points out the need for early diagnosis and treatment [19], which requires prior literacy training for the population on menstruation (through educational interventions) [20].

In all territories, aspects related to menstruation have traditionally been immersed in multiple myths and taboos, some of which persist today [21]. In addition, socially, there is still a tendency to conceal menstruation, as reflected in television adverts for menstruation-related products [22]. Seear [23] even pointed out that publicizing menstrual issues can make women more vulnerable to stigmatization, and various authors in the same vein highlight the need to implement new educational strategies in this regard [24,25].

Studies on the perception of menstrual normality are scarce, and no study to date has examined the perception of menstrual normality by young Spanish women, which could serve as a starting point to guide future literacy studies on menstrual health to contribute towards female empowerment.

The present study aimed to compare the menstrual characteristics and symptoms of female university students who report self-perceived normality concerning their cycles and menstruation with those who perceive abnormality.

\section{Materials and Methods}

\subsection{Design}

Cross-sectional descriptive study.

\subsection{Participants and Sample}

The inclusion criteria were women between the ages of 18 and 25 enrolled in the 2019-2020 nursing degree program at the University of Andalusia, Spain. The exclusion criteria were women with chronic or acute health problems manifesting as pain, women with diagnosed gynecological pathology, those who had undergone surgery for some gynecological and/or pelvic problem, and those who did not meet the inclusion criteria.

\subsection{Study Variables and Data Collection}

Data collection was carried out by means of an ad hoc paper questionnaire based on previous studies on menstrual problems. The questionnaire included socio-demographic issues, gynecological issues, and menstrual symptoms.

Anthropometric data were collected through self-reports of participants' weight and height, which allowed the calculation of the Body Mass Index (BMI). The main study variable was a closed-ended question concerning the self-perceived normality of a woman's menstrual cycle: do you consider your menstrual cycles to be normal or, on the contrary, do you perceive any or all menstrual 
characteristic(s) or symptom(s) to be abnormal? (Normal/Abnormal). The Visual Analog Scale (VAS) was included to evaluate the self-perceived intensity of menstrual pain from 0 to 10 in women who experienced suffering from menstrual pain; this was categorized according to previous studies, into mild (0-3) and moderate-severe (4-10) $[9,26,27]$. To identify the perceived health status, the Spanish version of the EuroQol-5 Dimension (EuroQol-5D) was included, which includes a vertical graph with the VAS from 0 to 100, in which 0 is the worst imaginable health status and 100 is the best imaginable health status $[5,28,29]$. The Andersch and Milsom Scale was also used to determine the severity of dysmenorrhea according to the following grades: grade 0 (menstruation is not painful and daily activity is unaffected), grade 1 (menstruation is painful but seldom inhibits normal activity, analgesics are seldom required and mild pain), grade 2 (daily activity affected, analgesics required and give relief so that absence from work or school is unusual and moderate pain), and grade 3 (activity clearly inhibited, poor effect of analgesics, vegetative symptoms, and severe pain). Four closed questions were included on: pain intensity (not painful/mild pain/moderate pain/severe pain), working ability (unaffected/rarely affected/moderately affected/clearly affected/clearly inhibited), systemic symptoms (none/few/apparent), need for analgesia (not required/rarely required/required/poor effect) [18,30-33]. Normal menstrual characteristics were considered regular cycles of 24 to 38 days, with bleeding lasting 4.5 to 8 days, and with 5 to $80 \mathrm{~mL}$ blood flow [1,2]. As the amount of menstrual bleeding is difficult to quantify, students were asked to consider the number of pads used per day, light ( $\leq 5$ pads/day), medium (5-7 pads/day), or heavy ( $\geq 7$ pads/day). A light or medium amount of flow was considered normal, whereas heavy was considered abnormal $[6,18]$.

\subsection{Ethics}

This study was approved by the Andalusia Research Ethics Committee (Code: 1013-N-19). Prior to the study, all participants signed the informed consent. Furthermore, the principles of the Declaration of Helsinki and the current data protection regulations were respected at all times.

\subsection{Statistical Analysis}

A descriptive analysis was performed in which quantitative variables were described by means and standard deviation, whereas qualitative variables were described using frequencies and percentages. A bivariate analysis was conducted using the chi-square test for comparison of categorical variables in women who reported that their cycles were normal, and those who considered their cycles as being abnormal. Moreover, the Student's t-test was used for comparison in the same groups of continuous quantitative variables. To compare self-perceived normality in women with different degrees of menstrual pain, the Chi-square for linear trends was used.

Finally, an age-adjusted, stepwise binary logistic regression was performed to predict the perception of cycle abnormality from the significant variables identified in the bivariate analysis. The significance level was set at 0.05 .

\section{Results}

\subsection{Sociodemographic, Anthropometric, and Gynecological Results}

In total, 270 young university women participated in the study, with an average age of $20.63 \pm 1.78$ years, weight of $60.07 \pm 9.29$, height of $164.10 \pm 6.23$, and BMI of $22.30 \pm 3.15 \mathrm{~kg} / \mathrm{m}^{2}$. Of these, $75.4 \%$ resided in an urban environment.

The mean self-perceived health status was $80.20 \pm 11.69$. Regarding gynecological characteristics, the mean age of menarche was $12.14 \pm 1.51$ years. Seventy-three per cent of participants reported a regular cycle, $79.8 \%$ a light-moderate amount of bleeding, $87.4 \%$ reported that their menstrual cycles were between 24 and 38 days, $63.7 \%$ referred that each cycle had one day of menstrual bleeding, and $21 \%$ reported that their menstruation was not painful. Finally, $28.5 \%$ reported using oral contraceptives (OCPs). 


\subsection{Perception of Normal Menstruation and Sociodemographic and Anthropometric Characteristics}

No differences were found when comparing age, weight, height, BMI, and perceived health status between women with self-perceived normal menstruation and those with abnormal menstruation. The proportion of women who perceived abnormality was slightly higher in urban women $(20.2 \%)$ than in rural women $(19 \%)(p>0.05)$.

\subsection{Self-Perceived Normal Menstruation and Menstrual Characteristics}

Up to $77.4 \%$ perceived their menstruation as normal and $19.6 \%$ stated that they did not have a normal menstruation in spite of not having been diagnosed with any gynecological problem.

Among the women who reported having normal menstruation, only $42.6 \%$ had normal menstrual characteristics in terms of regularity, frequency, duration, and blood flow, based on the analysis of responses to specific questions regarding menstrual characteristics. Therefore, $67.4 \%$ claimed to have normal menstruation; however, in their specific self-reports, concerning the characteristics of their menstrual cycles, some degrees of abnormalities were identified.

The mean age of menarche was similar in women who perceived normality $(12.14 \pm 1.48)$ versus those who did not $(12.06 \pm 1.52)(p>0.05)$.

Table 1 shows the comparison of menstrual characteristics in women with self-perception of normality and menstrual abnormality. Among women with an abnormal cycle length, there was also a higher percentage (33.3\%) of those who considered their menses to be abnormal than among those with normal cycle length $(18.3 \%)(p=0.045)$. Comparing the mean cycle length between women with self-perceived normal and abnormal cycle lengths, a higher mean cycle length was identified in those with perceived abnormality ( $30.92 \pm 7.54$ vs. $28.44 \pm 3.62 ; p=0.023)$.

Of the total participants who perceived normality, $56.6 \%$ had an irregular cycle as opposed to $43.4 \%$ who had a regular cycle $(p<0.01)$.

Table 1. Comparison of menstrual characteristics in women with self-perception of normality and menstrual abnormality.

\begin{tabular}{|c|c|c|c|c|c|}
\hline \multirow{2}{*}{ Menstrual Characteristics } & & \multicolumn{2}{|c|}{ Self-Perception of Your Menstrual Cycle } & \multirow{2}{*}{ Total } & \multirow{2}{*}{$p$-Value $^{\text {a }}$} \\
\hline & & Normal & Abnormal & & \\
\hline \multirow{2}{*}{ Regular menstrual cycle } & No & $42(58.3 \%)$ & $30(41.7 \%)$ & $72(27.5 \%)$ & \multirow{2}{*}{$0.000 *$} \\
\hline & Yes & $167(87.9 \%)$ & $23(12.1 \%)$ & $190(72.5 \%)$ & \\
\hline \multirow{2}{*}{ Duration of cycle } & Normal & $187(81.7 \%)$ & $42(18.3 \%)$ & $229(87.4 \%)$ & \multirow{2}{*}{$0.045^{*}$} \\
\hline & Abnormal & $22(66.7 \%)$ & $11(33.3 \%)$ & $33(12.6 \%)$ & \\
\hline \multirow{2}{*}{ Duration of menses } & Normal & $133(79.6 \%)$ & $34(20.4 \%)$ & $167(63.7 \%)$ & \multirow{2}{*}{0.945} \\
\hline & Abnormal & $76(80 \%)$ & $19(20 \%)$ & $95(36.3 \%)$ & \\
\hline \multirow{3}{*}{ Amount of flow } & Light & $29(80.6 \%)$ & $7(19.4 \%)$ & $36(13.7 \%)$ & \multirow{3}{*}{0.125} \\
\hline & Average & $143(82.7 \%)$ & $30(17.3 \%)$ & $173(66 \%)$ & \\
\hline & Heavy & $37(69.8 \%)$ & $16(30.2 \%)$ & $53(20.2 \%)$ & \\
\hline \multirow{2}{*}{ OCPs } & No & $150(78.5 \%)$ & $41(21.5 \%)$ & $191(72.9 \%)$ & \multirow{2}{*}{0.414} \\
\hline & Yes & $59(83.1 \%)$ & $12(16.9 \%)$ & $71(27.1 \%)$ & \\
\hline
\end{tabular}

\subsection{Normal Menstrual Perception and Menstrual Symptoms}

Of the total number of women who reported abnormal menstruation, $90.6 \%$ suffered from menstrual pain compared to $9.4 \%$ of those who did not report such pain $(p=0.021)$. However, of those who considered their menstruation to be normal, $76.1 \%$ also suffered from menstrual pain.

Women with menstrual pain were more frequently considered to have abnormal menstruation among those with Grade 3 pain (66.7\%) than in those with Grade $2(25.4 \%)$, Grade $1(9.7 \%)$, and Grade 0 $(9.1 \%)$ pain $(p<0.01)$. In relation to the intensity of menstrual pain when evaluated on the VAS Scale 
and categorized according to previous studies, $96.2 \%$ of women with moderate-severe pain intensity considered their menstrual cycle to be abnormal compared to $5.6 \%$ of those with more mild pain $(p=0.018)$.

Up to $98.1 \%$ of the women who considered their menstruation to be abnormal complained of tiredness during menstruation, compared to $1.9 \%$ of those who did not feel tired $(p=0.012)$. Moreover, $58.5 \%$ of those who showed abnormality perceived a decrease in concentration on the days of menstruation, which was higher than the percentage of those who did not perceive any alteration in their concentration $(41.5 \%)(p=0.009)$.

Among the women who suffered from dizziness during menstruation, in Table 2 it is shown that $31.1 \%$ considered their menstruation abnormal; however, among those who did not suffer from this symptom, only $16 \%$ considered it abnormal $(p=0.006)$.

Table 2. Comparison of menstrual symptoms in women with normal and abnormal menstrual periods.

\begin{tabular}{|c|c|c|c|c|c|}
\hline \multirow[b]{2}{*}{ Menstrual Symptoms } & & \multicolumn{2}{|c|}{ Self-Perception of Your Menstrual Cycle } & \multirow[b]{2}{*}{$\begin{array}{l}\text { Total } \\
n(\%)\end{array}$} & \multirow[b]{2}{*}{$p$-Value ${ }^{\text {a }}$} \\
\hline & & $\begin{array}{c}\text { Normal } \\
n(\%)\end{array}$ & $\begin{array}{c}\text { Abnormal } \\
n(\%)\end{array}$ & & \\
\hline \multirow{2}{*}{ Menstrual pain } & No & $50(90.9 \%)$ & $5(9.1 \%)$ & $55(21 \%)$ & \multirow{2}{*}{$0.021 *$} \\
\hline & Yes & $159(76.8 \%)$ & $48(23.2 \%)$ & $207(79 \%)$ & \\
\hline \multirow{2}{*}{ Change in appetite } & No & $37(86 \%)$ & $6(14 \%)$ & $43(16.5 \%)$ & \multirow{2}{*}{0.257} \\
\hline & Yes & $171(78.4 \%)$ & $47(21.6 \%)$ & $218(83.5 \%)$ & \\
\hline \multirow{2}{*}{ Nausea } & No & $159(84.6 \%)$ & $29(15.4 \%)$ & $188(71.8 \%)$ & \multirow{2}{*}{$0.002 *$} \\
\hline & Yes & $50(67.6 \%)$ & $24(32.4 \%)$ & $74(28.2 \%)$ & \\
\hline \multirow{2}{*}{ Vomiting } & No & $193(80.8 \%)$ & $46(19.2 \%)$ & $239(91.9 \%)$ & \multirow{2}{*}{0.124} \\
\hline & Yes & $14(66.7 \%)$ & $7(33.3 \%)$ & $21(8.1 \%)$ & \\
\hline \multirow{2}{*}{ Dizziness } & No & $158(84 \%)$ & $30(16 \%)$ & $188(71.8 \%)$ & \multirow[b]{2}{*}{$0.006 *$} \\
\hline & Yes & $51(68.9 \%)$ & $23(43.4 \%)$ & $74(28.2 \%)$ & \\
\hline \multirow{2}{*}{ Fatigue } & No & $30(96.8 \%)$ & $1(3.2 \%)$ & $31(11.8 \%)$ & \multirow{2}{*}{$0.012 *$} \\
\hline & Yes & $179(77.5 \%)$ & $52(22.5 \%)$ & $231(88.2 \%)$ & \\
\hline \multirow{2}{*}{ Headache } & No & $97(84.3 \%)$ & $18(15.7 \%)$ & $115(43.9 \%)$ & \multirow{2}{*}{0.103} \\
\hline & Yes & $112(76.2 \%)$ & $35(23.8 \%)$ & $147(56.1 \%)$ & \\
\hline \multirow{2}{*}{ Diarrhea } & No & $85(82.5 \%)$ & $18(17.5 \%)$ & $103(39.3 \%)$ & \multirow{2}{*}{0.372} \\
\hline & Yes & $124(78 \%)$ & $35(22 \%)$ & $159(60.7 \%)$ & \\
\hline \multirow{2}{*}{ Constipation } & No & $181(80.1 \%)$ & $45(19.9 \%)$ & $226(86.3 \%)$ & \multirow{2}{*}{0.749} \\
\hline & Yes & $28(77.8 \%)$ & $8(22.2 \%)$ & $36(13.7 \%)$ & \\
\hline \multirow{2}{*}{ Insomnia } & No & $166(80.2 \%)$ & $41(19.8 \%)$ & $207(79 \%)$ & \multirow{2}{*}{0.741} \\
\hline & Yes & $43(78.2 \%)$ & $12(21.8 \%)$ & $55(21 \%)$ & \\
\hline Irritability & No & $134(79.3 \%)$ & $35(20.7 \%)$ & $169(65.3 \%)$ & \\
\hline Irritability & Yes & $74(82.2 \%)$ & $16(17.8 \%)$ & $90(34.7 \%)$ & $0.5 \% 2$ \\
\hline Denreccive cumntoms & No & $67(82.7 \%)$ & 14(17.3\%) & $81(31 \%)$ & \\
\hline Depressive symptoms & Yes & $141(78.3 \%)$ & $39(21.7 \%)$ & $180(69 \%)$ & 0.415 \\
\hline & No & $128(85.3 \%)$ & $22(14.7 \%)$ & $150(57.3 \%)$ & \\
\hline Decreased concentration & Yes & $81(72.3 \%)$ & $31(27.7 \%)$ & $112(42.7 \%)$ & $0.009^{*}$ \\
\hline Pain appears or is worse when & No & $45(86.5 \%)$ & $7(13.5 \%)$ & $52(21.3 \%)$ & \\
\hline sitting & Yes & $148(77.1 \%)$ & $44(22.9 \%)$ & $192(78.7 \%)$ & 0.137 \\
\hline Pain appears or gets worse & No & $116(82.9 \%)$ & $24(17.1 \%)$ & $140(57.4 \%)$ & \\
\hline when you put on weight & Yes & $77(74 \%)$ & $27(26 \%)$ & $104(42.6 \%)$ & 0.094 \\
\hline Pain appears or is worse when & No & $83(88.3 \%)$ & $11(11.7 \%)$ & $94(38.7 \%)$ & \\
\hline walking & Yes & $109(73.2 \%)$ & $40(26.8 \%)$ & $149(61.3 \%)$ & $0.005^{*}$ \\
\hline Need to stop and sit down & No & $87(87.9 \%)$ & $12(12.1 \%)$ & $99(37.8 \%)$ & \\
\hline Need to stop and sit down & Yes & $122(74.8 \%)$ & $41(25.2 \%)$ & $163(62.2 \%)$ & $0.011^{*}$ \\
\hline & No & $149(81.4 \%)$ & $34(18.6 \%)$ & $183(76.3 \%)$ & \\
\hline Painful bowel movements & Yes & $42(73.7 \%)$ & $15(26.3 \%)$ & $57(23.8 \%)$ & 0.206 \\
\hline & No & $120(87 \%)$ & $18(13 \%)$ & $138(57.7 \%)$ & \\
\hline Pain with a full bladder & Yes & $70(69.3 \%)$ & $31(30.7 \%)$ & $101(42.3 \%)$ & $0.001^{*}$ \\
\hline & No & $153(80.5 \%)$ & $37(19.5 \%)$ & $190(79.2 \%)$ & \\
\hline Painful urination & Yes & $38(76 \%)$ & $12(24 \%)$ & $50(20.8 \%)$ & 0.480 \\
\hline & No & $153(80.5 \%)$ & $37(19.5 \%)$ & $190(77.9 \%)$ & \\
\hline Pain with sex & Yes & $40(74.1 \%)$ & $14(25.9 \%)$ & $54(22.1 \%)$ & 0.303 \\
\hline
\end{tabular}


Table 2. Cont.

\begin{tabular}{|c|c|c|c|c|c|}
\hline \multirow[b]{2}{*}{ Menstrual Symptoms } & & \multicolumn{2}{|c|}{ Self-Perception of Your Menstrual Cycle } & \multirow[b]{2}{*}{$\begin{array}{l}\text { Total } \\
n(\%)\end{array}$} & \multirow[b]{2}{*}{$p$-Value ${ }^{a}$} \\
\hline & & $\begin{array}{l}\text { Normal } \\
n(\%)\end{array}$ & $\begin{array}{l}\text { Abnormal } \\
n(\%)\end{array}$ & & \\
\hline \multirow{2}{*}{ Missing classes or practices } & No & $96(86.5 \%)$ & $15(13.5 \%)$ & $111(42.4 \%)$ & \multirow{2}{*}{$0.020 *$} \\
\hline & Yes & $113(74.8 \%)$ & $38(25.2 \%)$ & $151(57.6 \%)$ & \\
\hline \multirow{2}{*}{ Interferes with your daily life } & No & $113(89.7 \%)$ & $13(10.3 \%)$ & $126(48.3 \%)$ & \multirow{2}{*}{$0.000 *$} \\
\hline & Yes & $95(70.4 \%)$ & $40(29.6 \%)$ & $135(51.7 \%)$ & \\
\hline \multirow{2}{*}{$\begin{array}{c}\text { Interferes with your social } \\
\text { activities }\end{array}$} & No & $122(85.9 \%)$ & $20(14.1 \%)$ & $142(54.2 \%)$ & \multirow{2}{*}{$0.007^{*}$} \\
\hline & Yes & $87(72.5 \%)$ & $33(27.5 \%)$ & $120(45.8 \%)$ & \\
\hline
\end{tabular}

Of the total number of women who had to miss classes or clinical practice during their menstruation due to menstrual symptoms, only $25.2 \%$ considered their period to be abnormal. Moreover, of the total number of women who considered their period to be abnormal, $71.7 \%$ had missed some amount of class time or clinical practice training in the last year due to their period.

\subsection{Logistic Regression to Predict the Perception of Abnormal Menstruation}

Table 3 summarizes regression data to predict perceived menstrual abnormality from menstrual symptoms and characteristics. Women who suffered from dizziness during menstruation were identified as being $1.997(\mathrm{CI} 95 \%=1.010-3.950 ; p=0.047)$ times more likely to manifest abnormal menstruation, $4.518(\mathrm{CI} 95 \%=1.239-16.477 ; p=0.022)$ times more likely if they suffered Grade 3 menstrual pain and $2.851(\mathrm{CI} 95 \%=1.399-5.809 ; p=0.004)$ times more likely if they perceived that menstruation interfered with their daily lives.

Table 3. Binary logistic regression to predict the perception of abnormal menstrual periods from menstrual characteristics and symptoms reported by women.

\begin{tabular}{ccccc}
\hline Menstrual Characteristics and Symptoms & OR $^{\text {a }}$ & \multicolumn{2}{c}{ CI95\% } & $p$-Value \\
\hline Grade 3 & 4.518 & 1.239 & 16.477 & $0.022^{*}$ \\
Dizziness & 1.997 & 1.010 & 3.950 & $0.047^{*}$ \\
Interferes with your daily life & 2.851 & 1.399 & 5.809 & $0.004^{*}$ \\
\hline
\end{tabular}

$\mathrm{OR}^{\mathrm{a}}$ : Odds ratio age-adjusted; ${ }^{*} p<0.05$.

\section{Discussion}

Up to $77.4 \%$ of participants stated that their menstruation and menstrual cycle was normal; however, upon answering more specific questions, $67.4 \%$ stated abnormal characteristics. Having an irregular and abnormal cycle length were the cycle characteristics most commonly associated with self-perceived abnormality, the remaining alterations were perceived as normal in most young women.

In terms of symptoms, nausea, dizziness, tiredness, lack of concentration, and menstrual pain were most prevalent in women who reported an abnormal cycle. However, these findings also highlight that $76.1 \%$ of women who considered their cycle to be normal also suffered from menstrual pain. The perception of an abnormal cycle was also more frequent in women who stated that the pain appeared or intensified when walking, with a full bladder, when menstrual issues caused them to miss clinical practices, and when it interfered with their daily lives and social lives.

The regression showed that young women who suffered from menstrual dizziness were $1.997($ IC95\% $=1.010-3.950 ; p=0.047)$ times more likely to report abnormal menstruation, $4.518($ IC95\% $=1.239-16.477 ; p=0.022)$ times more likely if they had Grade 3 menstrual pain and $2.851(\mathrm{IC} 95 \%=1.399-5.809 ; p=0.004)$ times more likely if they perceived that menstruation interfered with their daily life.

The fact that more than half of the women $(67.4 \%)$ who reported normal menstruation had some kind of disorder shows that health science students are not aware of the normal characteristics of the 
menstrual cycle or are not able to apply the definition to their own health assessment. This is in line with previous findings, considering that the participants were nursing students and, therefore, had greater knowledge of gynecological health issues than the rest of the population [34]. Thus, it is assumed that higher percentages may be found in university students from other disciplines or in women without university studies. Therefore, there is a need to explore women's knowledge of menstrual normality in future studies, independently of their self-evaluation. Moreover, it seems necessary to implement educational strategies along these lines, because young women being able to identify their menstrual disorders is the first step for them to seek consultation with health professionals. Irregularity and abnormality in cycle length were the two menstrual characteristics associated with perception of abnormality, coinciding with those identified in previous studies in other countries and among young women in Spain [4,12-14]. It is likely that these characteristics may be of more concern to college girls as both characteristics may be associated with delayed menstruation, and there is also the possibility of an unwanted pregnancy, which is often a concern for female university students [35].

Menstrual pain was reported by $90.6 \%$ of those who expressed self-perceived abnormality of their menstrual cycle. Regarding the intensity of menstrual pain, $96.2 \%$ of women with moderate-severe intensity of menstrual pain manifested self-perceived abnormality. In relation to the degree of pain according to the Andersch and Milsom Scale, a higher percentage of women with perceived abnormality was identified with Grade 3 pain (66.7\%). A Grade 3 on this scale indicates that activity is clearly inhibited, together with a poor effect of analgesics, vegetative symptoms, and severe pain. It seems logical that women with this degree of pain have a greater perception of abnormality. Along the same lines, previous studies have already identified that women with a higher degree or severity of menstrual intensity have a poorer quality of life and a higher rate of absenteeism during menstruation [5,12,31]. However, in the current study, no association was found between the consumption of OCPs and the perception of normality, although it was expected that such an association would be found according to the previous literature that related the consumption of OCPs to a lower degree of dysmenorrhea (the Andersch and Milsom Scale) [33], and less menstrual absenteeism [12]. Our results could be attributed to the fact that it is likely that some of the participants consumed these OCPs to manage their self-perceived menstrual abnormality, and although improvement during consumption is common, it is likely that they manifest that their menstrual cycles as such are not normal. It should be noted that previous studies indicate that self-medication without consulting health professionals in young people with menstrual disorders is very common $[9,18]$ and, on the other hand, self-medication in general is also a frequent practice among nursing students [36,37]. Other symptoms more related to menstrual abnormality were nausea, dizziness, fatigue, and lack of concentration. Although it should be noted that some authors consider these symptoms related to menstrual pain itself, in our study, as in a previous one [12], we identified that they are also manifested in women who do not suffer from menstrual pain; therefore, it seems interesting to continue studying them individually, in women with and without dysmenorrhea. Nausea, dizziness, and menstrual pain had been previously linked to menstrual absenteeism in college women [12], which seems consistent with the results of this study, which identified a higher proportion of women with abnormalities who suffered from these symptoms and were absent from classes and/or clinical practices during menstruation.

The results of the regression have identified that women who suffer from dizziness, a Grade 3 in pain, and perceive that these symptoms interfere with their activities of daily living are more likely to perceive their cycles as being abnormal. This could be interpreted to mean that female perception of menstrual abnormalities are primarily based on whether or not they have very severe and limiting pain or symptoms that impact their daily lives, such as dizziness. All other abnormal characteristics and symptoms seem to go unnoticed by young women, because those who suffer from these characteristics do not usually manifest abnormality. When comparing these findings with the only study found on menstrual absenteeism among Spanish university women, there were coincidences in the detection of menstrual pain and dizziness as being more likely in women who are absent from classes and/or practical training during menstruation; however, in the former study, other symptoms were also 
identified as being more likely in women who missed class during their periods (nausea and vomiting, sleep disturbances, and feeling depressed) [12]. However, in the present study, only nausea was identified as a statistically more frequent symptom in those who considered their menstrual cycle to be abnormal. This variable did not enter the regression equation, suggesting that it should be further explored in future studies. Moreover, another study identified menstrual migraine as a factor related to menstrual absenteeism [38]. However, women with this symptom were not identified as having significantly higher perceptions of menstrual abnormalities in the current study, which may be due to the fact that young women may consider this menstrual symptom to be normal, as is the case with normalization of menstrual pain at Grade 0 and 1 [15].

The multiple myths and taboos related to menstruation that are still present in our society today are likely to be negatively influencing women's menstrual health [39] and can be explained in the context of a gender gap in women's health as self-silencing [40]. Although several studies have focused on the fact that women do not consult professionals for menstrual problems, our study assumes that perceiving cycle abnormality is the first step before consulting a health professional. The results of this study show that a high percentage of women with menstrual disorders are not aware of these and consider their cycles to be normal. Therefore, this highlights a significant knowledge gap in this regard that must be addressed, as reported in the qualitative study carried out by Wood et al. on the normality or abnormality of menstrual cycles in university women in Pennsylvania [41]. In addition, previous studies indicate that even women who perceive that their cycles are not normal usually fail to consult professionals as they believe that they will not assign any importance to these symptoms, or because of feelings of shame, or fear of being stigmatized by their close environments [15]. However, health professionals can assist these women in a number of ways, including reporting the available scientific evidence on lifestyle factors that positively and negatively influence menstrual characteristics and symptoms $[11,42,43]$.

Regarding symptom relief, the most explored menstrual symptom in the literature is relief from menstrual pain $[17,18,44]$. Furthermore, it has been identified that most women self-medicate with sub-therapeutic doses, which results in an unsuccessful approach [45]. Health professionals have an important role to play in this menstrual problem, as they can individually evaluate and detect secondary dysmenorrhea, advise on risk factors and protective factors, on the correct pharmacological approach, as well as report on non-pharmacological methods with proven efficacy that have fewer side effects, such as those based on physical exercise $[28,46]$. However, young women usually receive information about menstruation within their own families, from their mothers or sisters, yet, they are not sufficiently prepared to meet their needs [47,48]. Along these lines, Wong et al. pointed out that both the young woman's own menstrual education and the parents' level of education and training in this regard influence young women's menstrual behavior [49]. Currently, women also seek information on the internet due to its ease of accessibility, although the information on menstruation that these websites provide is often inaccurate and confusing [50]. For these reasons, in recent years, several authors have pointed out the need for greater menstrual literacy and have analyzed current educational interventions in this regard, stressing that these websites are having a poor effect in terms of dismantling taboos and menstrual myths $[21,24,25]$. It is therefore considered necessary to continue working on more effective interventions. These should be based on confidentiality, therapeutic communication, and culturally sensitive care, favoring women's empowerment $[39,51]$.

This study is the first to analyze the perception of menstrual normality and abnormality in Spanish women. It also provides the added value of comparing the menstrual characteristics and symptoms of both groups of women: those who perceive menstrual normality and those who do not, identifying the most influential aspects in the perception of abnormality. Furthermore, these findings highlight gaps in knowledge and/or self-evaluation among young people in relation to their menstrual normality or abnormality. Several studies indicate that the fact that women do not consult professionals regarding menstrual problems and decide to take care of themselves or self-medicate is a problem, as, in many cases this is inefficient management, or the problem is aggravated by the delay in consultation $[15,18]$. 
This study identifies a clear dissonance between the perceived abnormality and certain abnormal characteristics of the cycle when specifically analyzed, even though the group studied are students of health sciences. Thus, this population is expected to have more knowledge of the subject and greater ability to access scientific information related to health compared to other young people with lower levels of education. This underlines the need to improve the menstrual health literacy of all young women.

\section{Limitations}

These results must be interpreted while considering certain limitations due to the cross-sectional nature of this study, carried out in students from a single Spanish faculty. Additionally, the fact that all participants were a convenience sample of nursing students implies a selection bias, which seems to suggest that students from other non-health related disciplines may have a lesser agreement between perceived normality and normal menstrual characteristics. Another limitation is that only women under the age of 25 were included, which is considered in much of the gynecological literature as young women $[4,52,53]$. While this favored the homogeneity of the sample, facilitating comparison with the results of other studies, it also limits the possibility of generalizing the results towards women in other age ranges. Additionally, women with gynecological problems were excluded, although women with endocrine problems were not excluded, except those with polycystic ovary syndrome. This should be taken into account when interpreting the results, since other endocrine alterations, such as thyroid disorders, can influence menstrual characteristics [54,55]. Thus, in future studies it would be interesting to collect and analyze this variable. However, this paper is a first step in identifying information gaps and encourages further research into developing menstrual health education strategies from early stages. It would also be interesting for future studies to deepen our understanding of the influence of OCP consumption by performing a sensitivity analysis.

\section{Conclusions}

Most students consider their menstrual cycles and menses to be normal. However, a high percentage of women who consider their menstrual cycles to be normal have abnormal characteristics, menstrual symptoms, or both. Considering that the participants were nursing students, this reveals a deficit in knowledge in this subject or ability to correctly self-evaluate oneself that may be higher, still, in students from other non-health related disciplines. Self-perceived abnormality is considered key for women in order to seek healthcare. Therefore, it is necessary to direct health policies and strategies to improve knowledge of menstrual health, raise awareness of menstrual problems, and promote a comprehensive approach among health professionals towards menstrual health among young women.

Author Contributions: Conceptualization, A.A.-S. and E.F.-M.; methodology, E.F.-M.; software, E.F.-M.; validation, A.A.-S. and E.F.-M.; formal analysis, E.F.-M.; investigation, E.F.-M.; resources, E.F.-M.; data curation, E.F.-M. writing—original draft preparation A.A.-S. and E.F.-M.; writing—review and editing, A.A.-S., M.L.P.-F., M.D.O.-Z., and E.F.-M.; visualization, A.A.-S., M.L.P.-F., M.D.O.-Z., and E.F.-M.; supervision, E.F.-M. and A.A.-S.; project administration, E.F.-M.; funding acquisition, A.A.-S. All authors have read and agreed to the published version of the manuscript.

Funding: This research received no external funding.

Acknowledgments: The authors thank all of the women who participated in the study for their selfless collaboration in the study. We thank Isabel Quintero for her collaboration in the linguistic review and proofreading of this manuscript.

Conflicts of Interest: The authors declare no conflict of interest. 


\section{References}

1. Mihm, M.; Gangooly, S.; Muttukrishna, S. The normal menstrual cycle in women. Anim. Reprod. Sci. 2011, 124, 229-236. [CrossRef] [PubMed]

2. Munro, M.G. Classification of menstrual bleeding disorders. Rev. Endocr. Metab. Disord. 2012, 13, $225-234$. [CrossRef] [PubMed]

3. Williams, C.E.; Creighton, S.M. Menstrual disorders in adolescents: Review of current practice. Horm. Res. Paediatr. 2012, 78, 135-143. [CrossRef] [PubMed]

4. Armour, M.; Parry, K.; Manohar, N.; Holmes, K.; Ferfolja, T.; Curry, C.; MacMillan, F.; Smith, C.A. The Prevalence and Academic Impact of Dysmenorrhea in 21,573 Young Women: A Systematic Review and Meta-Analysis. J. Women's Health 2019, 28, 1161-1171. [CrossRef] [PubMed]

5. Fernández-Martínez, E.; Onieva-Zafra, M.D.; Parra-Fernández, M.L. The Impact of Dysmenorrhea on Quality of Life Among Spanish Female University Students. Int. J. Environ. Res. Public Health 2019, 16, 713. [CrossRef]

6. Ansong, E.; Arhin, S.K.; Cai, Y.; Xu, X.; Wu, X. Menstrual characteristics, disorders and associated risk factors among female international students in Zhejiang Province, China: A cross-sectional survey. BMC Womens. Health 2019, 19, 35. [CrossRef]

7. Romito, P.; Cedolin, C.; Bastiani, F.; Beltramini, L.; Saurel-Cubizolles, M.J. Sexual harassment and menstrual disorders among Italian university women: A cross-sectional observational study. Scand. J. Public Health 2017, 45, 528-535. [CrossRef]

8. Iacovides, S.; Avidon, I.; Baker, F.C. What we know about primary dysmenorrhea today: A critical review. Hum. Reprod. Update 2015, 21, 762-778. [CrossRef]

9. Fernández-Martínez, E.; Onieva-Zafra, M.D.; Parra-Fernández, M.L. Lifestyle and prevalence of dysmenorrhea among Spanish female university students. PLoS ONE 2018, 13, e0201894. [CrossRef]

10. Abreu-Sánchez, A.; Parra-Fernández, M.L.; Onieva-Zafra, M.D.; Ramos-Pichardo, J.D.; Fernández-Martínez, E. Type of Dysmenorrhea, Menstrual Characteristics and Symptoms in Nursing Students in Southern Spain. Healthcare 2020, 8, 302. [CrossRef]

11. Onieva-Zafra, M.D.; Fernández-Martínez, E.; Abreu-Sánchez, A.; Iglesias-López, M.T.; García-Padilla, F.M.; Pedregal-González, M.; Parra-Fernández, M.L. Relationship between diet, menstrual pain and other menstrual characteristics among Spanish students. Nutrients 2020, 12, 1759. [CrossRef]

12. Fernández-Martínez, E.; Onieva-Zafra, M.D.; Abreu-Sánchez, A.; Fernández-Muñóz, J.J.; Parra-Fernández, M.L. Absenteeism during menstruation among nursing students in Spain. Int. J. Environ. Res. Public Health 2020, 17, 53. [CrossRef]

13. Schoep, M.E.; Nieboer, T.E.; van der Zanden, M.; Braat, D.D.M.; Nap, A.W. The impact of menstrual symptoms on everyday life: A survey among 42,879 women. Am. J. Obstet. Gynecol. 2019, 220, 569.e1-569.e7. [CrossRef]

14. Chen, C.X.; Draucker, C.B.; Carpenter, J.S. What women say about their dysmenorrhea: A qualitative thematic analysis. BMC Womens. Health 2018, 18, 47. [CrossRef] [PubMed]

15. Chen, C.X.; Shieh, C.; Draucker, C.B.; Carpenter, J.S. Reasons women do not seek health care for dysmenorrhea. J. Clin. Nurs. 2018, 27, e301-e308. [CrossRef] [PubMed]

16. Takemoto, D.M.; Beharry, M.S. What's normal? Accurately and efficiently assessing menstrual function. Pediatr. Ann. 2015, 44, e213-e217. [CrossRef]

17. Armour, M.; Smith, C.A.; Steel, K.A.; MacMillan, F. The effectiveness of self-care and lifestyle interventions in primary dysmenorrhea: A systematic review and meta-analysis. BMC Complement. Altern. Med. 2019, 19. [CrossRef]

18. Parra-Fernández, M.L.; Onieva-Zafra, M.D.; Abreu-Sánchez, A.; Ramos-Pichardo, J.D.; Iglesias-López, M.T.; Fernández-Martínez, E. Management of Primary Dysmenorrhea among University Students in the South of Spain and Family Influence. Int. J. Environ. Res. Public Health 2020, 17, 5570. [CrossRef] [PubMed]

19. Adams Hillard, P.J. Menstruation in adolescents: What's normal, what's not. Ann. N. Y. Acad. Sci. 2008, 1135, 29-35. [CrossRef] [PubMed]

20. Matteson, K.A.; Zaluski, K.M. Menstrual Health as a Part of Preventive Health Care. Obstet. Gynecol. Clin. N. Am. 2019, 46, 441-453. [CrossRef]

21. Yagnik, A. Theorizing a model information pathway to mitigate the menstrual taboo. Health Promot. Int. 2019, 34, 410-419. [CrossRef] [PubMed] 
22. Tan, D.A.; Haththotuwa, R.; Fraser, I.S. Cultural aspects and mythologies surrounding menstruation and abnormal uterine bleeding. Best Pract. Res. Clin. Obstet. Gynaecol. 2017, 40, 121-133. [CrossRef] [PubMed]

23. Seear, K. The etiquette of endometriosis: Stigmatisation, menstrual concealment and the diagnostic delay. Soc. Sci. Med. 2009, 69, 1220-1227. [CrossRef]

24. Wilson, E.; Haver, J.; Torondel, B.; Rubli, J.; Caruso, B.A. Dismantling menstrual taboos to overcome gender inequality. Lancet Child Adolesc. Health 2018, 2, e17. [CrossRef]

25. Rastogi, S.; Khanna, A.; Mathur, P. Educational interventions to improve menstrual health: Approaches and challenges. Int. J. Adolesc. Med. Health 2019, 1. [CrossRef]

26. Hawker, G.A.; Mian, S.; Kendzerska, T.; French, M. Measures of adult pain: Visual analog scale for pain (vas pain), numeric rating scale for pain (nrs pain), mcgill pain questionnaire (mpq), short-form mcgill pain questionnaire (sf-mpq), chronic pain grade scale (cpgs), short form-36 bodily pain scale (sf-36 bps), and measure of intermittent and constant osteoarthritis pain (icoap). Arthritis Care Res. (Hoboken) 2011, 63, S240-S252. [PubMed]

27. Collins, S.L.; Moore, R.A.; McQuay, H.J. The visual analogue pain intensity scale: What is moderate pain in millimetres? Pain 1997, 72, 95-97. [CrossRef]

28. McGovern, C.E.; Cheung, C. Yoga and Quality of Life in Women with Primary Dysmenorrhea: A Systematic Review. J. Midwifery Women's Health 2018, 63, 470-482. [CrossRef]

29. Igwea, S.E.; Tabansi-Ochuogu, C.S.; Abaraogu, U.O. TENS and heat therapy for pain relief and quality of life improvement in individuals with primary dysmenorrhea: A systematic review. Complement. Ther. Clin. Pract. 2016, 24, 86-91. [CrossRef]

30. Bazarganipour, F.; Lamyian, M.; Heshmat, R.; Abadi, M.A.J.; Taghavi, A. A randomized clinical trial of the efficacy of applying a simple acupressure protocol to the Taichong point in relieving dysmenorrhea. Int. J. Gynecol. Obstet. 2010, 111, 105-109. [CrossRef]

31. Tomás-Rodríguez, M.I.;Palazón-Bru, A.; Martínez-St John, D.R.J.;Navarro-Cremades, F.; Toledo-Marhuenda, J.V.; Gil-Guillén, V.F. Factors Associated with Increased Pain in Primary Dysmenorrhea: Analysis Using a Multivariate Ordered Logistic Regression Model. J. Pediatr. Adolesc. Gynecol. 2017, 30, 199-202. [CrossRef] [PubMed]

32. Sahin, M.E.; Sahin, E.; Madendag, Y.; Madendag, I.C.; Tayyar, A.T.; Özdemir, F.; Acmaz, G.; Muderris, I.I. The Effect of Anterior Uterocervical Angle on Primary Dysmenorrhea and Disease Severity. Pain Res. Manag. 2018, 2018, 9819402. [CrossRef] [PubMed]

33. Lindh, I.; Andersson Ellströ, A.; Milsom, I. The effect of combined oral contraceptives and age on dysmenorrhoea: An epidemiological study. Hum. Reprod. 2012, 27, 676-682. [CrossRef] [PubMed]

34. Seven, M.; Güvenç, G.; Akyüz, A.; Eski, F. Evaluating dysmenorrhea in a sample of Turkish nursing students. Pain Manag. Nurs. 2014, 15, 664-671. [CrossRef] [PubMed]

35. Hickey, M.T.; White, J. Female college students' experiences with and perceptions of over-the-counter emergency contraception in the United States. Sex. Reprod. Healthc. 2015, 6, 28-32. [CrossRef] [PubMed]

36. Williams, A.; Crawford, K. Self-medication practices among undergraduate nursing and midwifery students in Australia: A cross-sectional study. Contemp. Nurse 2016, 52, 410-420. [CrossRef]

37. Soroush, A.; Abdi, A.; Andayeshgar, B.; Vahdat, A.; Khatony, A. Exploring the perceived factors that affect self-medication among nursing students: A qualitative study. BMC Nurs. 2018, 17. [CrossRef]

38. Fernández-Martínez, E.; Onieva-Zafra, M.D.; Abreu-Sánchez, A.; González-Sanz, J.D.; Iglesias-López, M.T.; Fernández-Muñoz, J.J.; Parra-Fernández, M.L. Menstrual migraine among Spanish university students. J. Pediatr. Nurs. 2020. [CrossRef]

39. Agampodi, T.C.; Agampodi, S.B. The Lancet Child \& Adolescent Health Normalising menstruation, empowering girls. Lancet Child Adolesc. Health 2018, 2, e16.

40. Maji, S.; Dixit, S. Self-silencing and women's health: A review. Int. J. Soc. Psychiatry 2019, 65, 3-13. [CrossRef]

41. Wood, J.M.; Koch, P.B.; Mansfield, P.K. Is my period normal? How college-aged women determine the normality or abnormality of their menstrual cycles. Women Health 2007, 46, 41-56. [CrossRef] [PubMed]

42. Bajalan, Z.; Alimoradi, Z.; Moafi, F. Nutrition as a potential factor of primary dysmenorrhea: A systematic review of observational studies. Gynecol. Obstet. Investig. 2019, 84, 209-224. [CrossRef] [PubMed]

43. Lim, H.S.; Kim, T.H.; Lee, H.H.; Park, Y.H.; Lee, B.R.; Park, Y.J.; Kim, Y.S. Fast food consumption alongside socioeconomic status, stress, exercise, and sleep duration are associated with menstrual irregularities in Korean 
adolescents: Korea National Health and Nutrition Examination Survey 2009-2013. Asia Pac. J. Clin. Nutr. 2018, 27, 1146-1154. [PubMed]

44. Armour, M.; Parry, K.; Al-Dabbas, M.A.; Curry, C.; Holmes, K.; MacMillan, F.; Ferfolja, T.; Smith, C.A. Self-care strategies and sources of knowledge on menstruation in 12,526 young women with dysmenorrhea: A systematic review and meta-analysis. PLoS ONE 2019, 14, e0220103. [CrossRef]

45. Sugumar, R.; Krishnaiah, V.; Channaveera, G.S.; Mruthyunjaya, S. Comparison of the pattern, efficacy, and tolerability of self-medicated drugs in primary dysmenorrhea: A questionnaire based survey. Indian J. Pharmacol. 2013, 45, 180-183. [CrossRef]

46. Carroquino-Garcia, P.; Jiménez-Rejano, J.J.; Medrano-Sanchez, E.; De La Casa-Almeida, M.; Diaz-Mohedo, E.; Suarez-Serrano, C. Therapeutic Exercise in the Treatment of Primary Dysmenorrhea: A Systematic Review and Meta-Analysis. Phys. Ther. 2019, 99, 1371-1380. [CrossRef]

47. Chandra-Mouli, V.; Patel, S.V. Mapping the knowledge and understanding of menarche, menstrual hygiene and menstrual health among adolescent girls in low- and middle-income countries. Reprod. Health 2017, 14. [CrossRef]

48. De Sanctis, V.; Soliman, A.T.; Elsedfy, H.; Soliman, N.A.; Elalaily, R.; El Kholy, M. Dysmenorrhea in adolescents and young adults: A review in different countries. Acta Biomed. 2016, 87, 233-246.

49. Wong, C.L.; Ip, W.Y.; Choi, K.C.; Lam, L.W. Examining Self-Care Behaviors and Their Associated Factors Among Adolescent Girls with Dysmenorrhea: An Application of Orem's Self-Care Deficit Nursing Theory. J. Nurs. Scholarsh. 2015, 47, 219-227. [CrossRef]

50. Hillard, P.J.A. Menstruation in Adolescents: What Do We Know and What Do We Do with the Information. J. Pediatr. Adolesc. Gynecol. 2014, 27, 309-319. [CrossRef]

51. McEvoy, M.; Chang, J.; Coupey, S.M. Common menstrual disorders in adolescence: Nursing interventions. MCN Am. J. Matern. Nurs. 2004, 29, 41-49. [CrossRef] [PubMed]

52. Gallagher, J.S.; DiVasta, A.D.; Vitonis, A.F.; Sarda, V.; Laufer, M.R.; Missmer, S.A. The Impact of Endometriosis on Quality of Life in Adolescents. J. Adolesc. Heal. 2018, 63, 766-772. [CrossRef] [PubMed]

53. Flavin, M.; Shore, B.J.; Miller, P.; Gray, S. Hormonal Contraceptive Prescription in Young Women with Cerebral Palsy. J. Adolesc. Heal. 2019, 65, 405-409. [CrossRef] [PubMed]

54. Kakuno, Y.; Amino, N.; Kanoh, M.; Kawai, M.; Fujiwara, M.; Kimura, M.; Kamitani, A.; Saya, K.; Shakuta, R.; Nitta, S.; et al. Menstrual disturbances in various thyroid diseases. Endocr. J. 2010, 57, 1017-1022. [CrossRef]

55. Krassas, G.E.; Markou, K.B. The impact of thyroid diseases starting from birth on reproductive function. Hormones 2019, 18, 365-381. [CrossRef] 